\title{
Experimental and Numerical Study of the Effects of Acoustic Sound Absorbers on the Cooling Performance of Thermally Active Building Systems
}

Domínguez, L. Marcos ; Kazanci, Ongun Berk; Rage, Nils; Olesen, Bjarne W.

Published in:

Building and Environment

Link to article, DOI:

10.1016/j.buildenv.2017.02.009

Publication date:

2017

Document Version

Peer reviewed version

Link back to DTU Orbit

Citation (APA):

Domínguez, L. M., Kazanci, O. B., Rage, N., \& Olesen, B. W. (2017). Experimental and Numerical Study of the Effects of Acoustic Sound Absorbers on the Cooling Performance of Thermally Active Building Systems. Building and Environment, 116, 108-120. https://doi.org/10.1016/j.buildenv.2017.02.009

\section{General rights}

Copyright and moral rights for the publications made accessible in the public portal are retained by the authors and/or other copyright owners and it is a condition of accessing publications that users recognise and abide by the legal requirements associated with these rights.

- Users may download and print one copy of any publication from the public portal for the purpose of private study or research.

- You may not further distribute the material or use it for any profit-making activity or commercial gain

- You may freely distribute the URL identifying the publication in the public portal 


\title{
Experimental and Numerical Study of the Effects of Acoustic
} Sound Absorbers on the Cooling Performance of Thermally

\section{Active Building Systems}

\author{
L. Marcos Domínguez*, Ongun B. Kazanci, Nils Rage, Bjarne W. Olesen
}

International Centre for Indoor Environment and Energy - ICIEE, Department of Civil Engineering, Technical University of Denmark, Nils Koppels Allé, Building 402, 2800 Kgs. Lyngby, Denmark

* Corresponding author. E-mail address: marcosdomin@outlook.com

\begin{abstract}
Free-hanging horizontal and vertical sound absorbers are commonly used in buildings for room acoustic control; however, when these sound absorbers are used in combination with Thermally Active Building Systems, they will decrease the cooling performance of Thermally Active Building Systems and this will affect the thermal indoor environment in that space. Therefore, it is crucial to be able to quantify and model these effects in the design phase.
\end{abstract}

This study quantifies experimentally the effects of horizontal and vertical free-hanging sound absorbers on the cooling performance of Thermally Active Building Systems and on the thermal indoor environment. The experiments were carried out in a climate chamber configured as a two-person office room. Different ceiling coverage ratios were tested. In addition, a commercially available dynamic building simulation software was 
used with a recently developed plug-in for acoustic elements, which allows modeling free-hanging horizontal sound absorbers that partially cover the ceiling.

With horizontal sound absorbers, the cooling performance of the Thermally Active Building System decreased by $11 \%, 23 \%$ and $36 \%$ for ceiling coverage ratios of $43 \%, 60 \%$ and $80 \%$, respectively. With vertical sound absorbers, the decrease in cooling performance was $8 \%, 12 \%$, and $14 \%$ for the corresponding cases, respectively. The numerical model predicted closely the cooling performance reduction, air temperatures and ceiling surface temperatures in most cases, while there were differences in mean radiant temperatures and cooling capacity coefficients, indicating that the model can be improved in certain aspects.

\section{Keywords}

TABS; thermal environment; sound absorption; cooling capacity; Full-scale measurements; building simulations

\section{Nomenclature}

$\begin{array}{ll}\mathrm{A}_{\text {deck }} & \text { Area of the deck }\left[\mathrm{m}^{2}\right] \\ \mathrm{c}_{\mathrm{p}} & \text { Specific heat capacity of the fluid in the pipes }[\mathrm{J} /(\mathrm{kg} \mathrm{K})] \\ \dot{\mathrm{m}} & \text { Mass flow rate of the fluid in the pipes }[\mathrm{kg} / \mathrm{s}] \\ \mathrm{q}_{\text {down }} & \text { Heat flow through the floor covering }[\mathrm{W}] \\ \mathrm{q}_{\text {guard }} & \text { Heat flow between the sides of the deck and the guard [W] } \\ \mathrm{q}_{\text {pipe }} & \text { Heat flow through the ceiling surface }[\mathrm{W}] \\ \mathrm{q}_{\text {up }} & \end{array}$


$\mathrm{R}_{\text {floor covering }} \quad$ Resistance of the floor covering $\left[\left(\mathrm{m}^{2} \mathrm{~K}\right) / \mathrm{W}\right]$

$\mathrm{T}_{\text {fluid }} \quad$ Average temperature of the fluid in the decks $\left[{ }^{\circ} \mathrm{C}\right]$

$\mathrm{T}_{\text {return }} \quad$ Return temperature of the fluid in the pipes $\left[{ }^{\circ} \mathrm{C}\right]$

$\mathrm{T}_{\text {room }} \quad$ Operative temperature in the room $\left[{ }^{\circ} \mathrm{C}\right]$

$\mathrm{T}_{\text {supply }} \quad$ Supply temperature of the fluid in the pipes $\left[{ }^{\circ} \mathrm{C}\right]$

$\mathrm{U}_{\mathrm{cc}} \quad$ Cooling capacity coefficient of the ceiling $\left[\mathrm{W} /\left(\mathrm{m}^{2} \mathrm{~K}\right)\right]$

$\Delta \mathrm{T}_{\text {floor covering }} \quad$ Temperature difference between the upper and lower surfaces of the floor covering $\left[{ }^{\circ} \mathrm{C}\right]$ 


\section{Introduction}

The main function of a building is to create a healthy and comfortable indoor environment for its occupants. Heating, cooling, and ventilation systems enable controlling the indoor environmental conditions to achieve optimal conditions for human occupancy. One particular group of heating and cooling systems in buildings is water-based radiant surface heating and cooling systems, where at least half of the heat transfer from the heated or cooled surface is by radiation [1]. An example of water-based radiant surface heating and cooling systems is Thermally Active Building Systems (TABS).

TABS benefit from the activation and control of building thermal mass by means of circulating heated or chilled water through the pipes that are embedded in main concrete construction slabs exposed to the indoor environment. The thermal indoor environment is controlled by emitting or removing heat from the indoor space by TABS surfaces (normally the ceiling surface), and by adding or extracting heat from the TABS structure by water circulation. Radiant systems and TABS have several advantages, such as benefiting from the low temperature heating and high temperature cooling principle [2], [3], [4], [5], possibility of coupling with renewable heat sources and sinks [6], [7], [8], possibility of transferring peak heating and cooling loads to offpeak hours and peak load reductions [1], [9], [10], [11].

Indoor conditions for satisfying occupants are not only thermal, but also factors such as lighting and acoustics are crucial to consider. Regarding the acoustics, one particular challenge is the use of TABS with sound absorbers hanging from the ceiling (free-hanging sound absorbers). TABS use large building surfaces to emit or remove heat, therefore require unobstructed surfaces, which could have a negative impact on the acoustic quality of indoor spaces [4], [12]. Therefore, using free-hanging sound absorbers in combination with TABS poses a 
challenge. Acoustic solutions that are capable of providing optimal acoustic comfort while allowing the heat exchange between the TABS and the room are desirable.

It is important to quantify the effects of horizontal and vertical sound absorbers on the cooling capacity of TABS in order to design accurately the systems, and to be able to predict the corresponding effects on the thermal indoor environment in terms of temperature increase. Different authors have studied the effects of sound absorbers on cooling performance of TABS by climate chamber measurements [13], [14], [15], [16], [17], [18], by field measurements [19], [20], [21], [22], and more recently by dynamic building simulations [23], [24], [25], [26].

Pittarello [13], and Weitzmann et al. [14] studied the cooling capacity of TABS combined with acoustic ceiling using different ceiling coverage ratios with both horizontal and vertical free-hanging sound absorbers, and showed that it was possible to combine TABS and acoustic ceilings. Furthermore, they also showed that covering up to the $50 \%$ of the ceiling area did not have a remarkable effect on the cooling performance of TABS, and that using vertical sound absorbers did not lower the cooling capacity noticeably. Peperkamp and Vercammen [15], and Vercammen [16] studied experimentally the effects of horizontal sound absorbers on the cooling capacity of TABS with different ceiling coverage ratios. Their results show that if half of the ceiling is covered with horizontal sound absorbers, the cooling capacity of the ceiling reduces by approximately $20 \%$ and that the distance between the ceiling surface and the horizontal sound absorbers does not have a remarkable effect on the cooling capacity of the ceiling. Similar measurements in climate chambers have also been performed by testing institutes [17], [18].

Muet et al. [19] reported measurements from an office building in France. The authors showed that the operative temperature increased by $0.3 \mathrm{~K}$ when the ceiling coverage ratio was $50 \%$ and the operative temperature increased by 0.8 to $1.0 \mathrm{~K}$ when the ceiling coverage ratio was $70 \%$. Muet and Lombard [20] reported 
measurements from an office building in Germany, where the authors tested different ceiling coverage ratios with horizontal sound absorbers and with vertical sound absorbers. The authors showed that satisfactory levels of thermal comfort could be achieved with ceiling coverage ratios of $45 \%$ and up to $60 \%$ in certain cases. The authors also stated that occupant behavior is an important factor affecting the thermal indoor environment conditions, in addition to the effects of the sound absorbers. Machner [21] also pointed out the effects of occupant behavior on the thermal indoor environment and stated that the impact of sound absorbers on the thermal indoor environment becomes secondary for ceiling coverage ratios lower than $60 \%$. Drotleff et al. [22] studied the effects of integrated sound absorbers (strips) in TABS ceilings on thermal indoor environment in an office room and found no significant effect for a $20 \%$ surface coverage. However, their study did not use freehanging sound absorbers.

Lombard [23] developed a numerical model of free-hanging horizontal sound absorbers, which can be implemented in different building simulation software. Using this model in a dynamic building simulation software, Rage et al. [24], [25] created a numerical model of a climate chamber that is equipped with TABS floor and ceiling decks and with horizontal sound absorbers. The authors validated the model with previous measurements [24], and used this validated model to carry out sensitivity analyses (e.g. different ceiling coverage ratios, different distances between the ceiling and the horizontal sound absorbers, different supply water temperatures to the TABS decks, different supply air temperatures from the ventilation system, and so forth) [25]. Langner and Bewersdorff [26] simulated the effects of horizontal sound absorbers on the thermal indoor environment in an open plan office that was cooled by TABS. The authors showed that the room temperatures were not affected significantly up to a ceiling coverage ratio of $50 \%$, and that a ceiling coverage ratio of more than $60 \%$ was necessary to exceed a room temperature of $25^{\circ} \mathrm{C}$ significantly. The authors also 
showed that room temperatures of $27^{\circ} \mathrm{C}$ would not be exceeded unless $80 \%$ of the ceiling surface was covered by horizontal sound absorbers.

Fredriksson and Sandberg [27] studied experimentally the effects of a false ceiling on the cooling capacity of a passive chilled beam. Høseggen et al. [28] studied experimentally and numerically the effects of suspended ceilings on the energy performance and thermal indoor environment in an office building in Norway. Morey et al. [29] used Computational Fluid Dynamics (CFD) to study the effects of accessing the concrete slab above suspended ceilings via perimeter gaps. Even though these authors reported on the effects of suspended ceilings, their studies did not include TABS, and therefore did not include a combination of suspended ceilings (or acoustic sound absorbers) with TABS.

In addition to these studies, there is still a further need to quantify the effects of using sound absorbers in combination with TABS, especially under different ceiling coverage ratios, when using different types of sound absorbers (horizontal panels or vertical baffles), and by validating commercially available dynamic building simulation software.

In this context, measurements were carried out in a climate chamber configured as a two-person office room in order to quantify the effects of horizontal and vertical free-hanging sound absorbers on the cooling performance of TABS and on the thermal indoor environment. Different ceiling coverage ratios were tested. In addition to the climate chamber measurements, dynamic building simulations were carried out using a commercially available software [30], with a special plug-in [23] that allows simulating the effects of horizontal sound absorbers on the cooling performance of TABS and on the thermal indoor environment. The simulation results were compared to the measurement results. 


\section{Methods}

This study consists of experiments conducted in a test facility under controlled conditions and of numerical investigations using a commercially available dynamic building simulation software. The details of these investigations are explained in the following.

\subsection{Details of the test facility}

The experiments were carried out in a test facility (climate chamber) located at the Technical University of Denmark, which had a room-in-a-room construction. The climate chamber was placed inside a guard, which surrounded the climate chamber. The temperature in the guard was controlled to have the same temperature in the climate chamber, in order to avoid heat losses or gains.

The climate chamber was configured as a two-person office room, equipped with floor and ceiling TABS decks and had a length of $6.0 \mathrm{~m}$ and a width of $3.6 \mathrm{~m}$ corresponding to a floor area of $21.6 \mathrm{~m}^{2}$. The room height was $3.6 \mathrm{~m}$, which allowed making modifications to the ceiling structure.

The walls consisted of plywood boards and insulation (U-value of $0.36 \mathrm{~W} /\left(\mathrm{m}^{2} \mathrm{~K}\right)$ ). The floor and ceiling consisted of thermally active concrete decks to obtain realistic conditions of a multi-story building with TABS. Each TABS deck consisted of three prefabricated hollow core concrete decks covering the entire area of the ceiling and floor. The slabs had a total thickness of $270 \mathrm{~mm}$. There was a wooden floor covering with a thickness of $15 \mathrm{~mm}$ and with a thermal conductivity of $0.15 \mathrm{~W} /(\mathrm{m} \mathrm{K})$. There was a $20 \mathrm{~mm}$ air gap between the floor covering and the concrete slab. PEX pipes of $20 \mathrm{~mm}$ outer diameter and $2 \mathrm{~mm}$ thickness were embedded in the concrete slabs with a pipe spacing of $150 \mathrm{~mm}$. The pipes were embedded at a depth of $50 \mathrm{~mm}$ from the lower surface of the deck. Fig. 1 shows the details of the test facility and the details of the TABS deck. 
a)

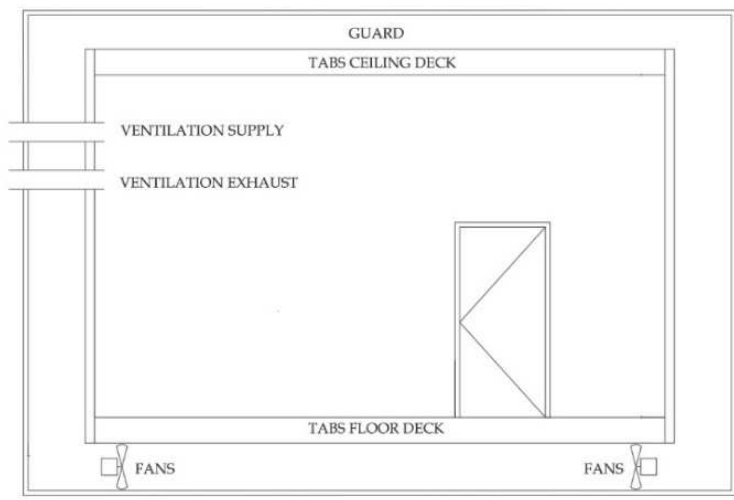

b)

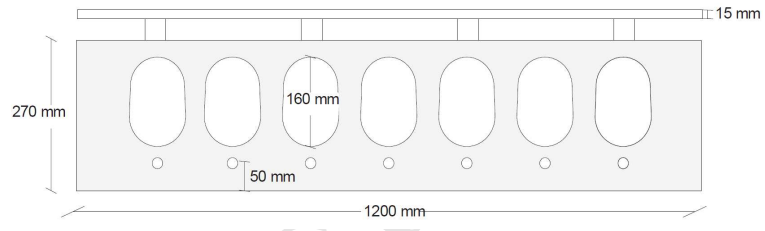

Fig. 1. Descriptive geometries of a) Test facility, b) One prefabricated concrete deck.

2.2. Details of the experimental setup with acoustic panels

Before installing the acoustic panels with different coverage ratios (the ratio of the ceiling area covered by freehanging sound absorbers to the total ceiling area), measurements were carried out without any acoustic panels (bare-ceiling, cooled TABS surface facing the room directly without any obstructions). This case was used as the reference case for the cooling performance of TABS and the thermal indoor environment.

Two types of free-hanging sound absorber units were tested with different ceiling coverage ratios. These sound absorber units were identified to be compatible with the performance of TABS [31], i.e. they allow heat exchange between the TABS and the room through convection and radiation, partially. One type corresponds to horizontal sound absorbers (Fig. 2, a), and the second type corresponds to vertical sound absorbers, baffles (Fig. 2, b). The panels are made of high-density glass wool with the dimensions of $1160 \mathrm{~mm}$ x $1000 \mathrm{~mm}$ and 1200 $\mathrm{mm}$ x $300 \mathrm{~mm}$ for horizontal and vertical panels, respectively, and a thickness of $40 \mathrm{~mm}$. Fig. 2 shows the dimensions of the sound absorbers used in the experiments. 

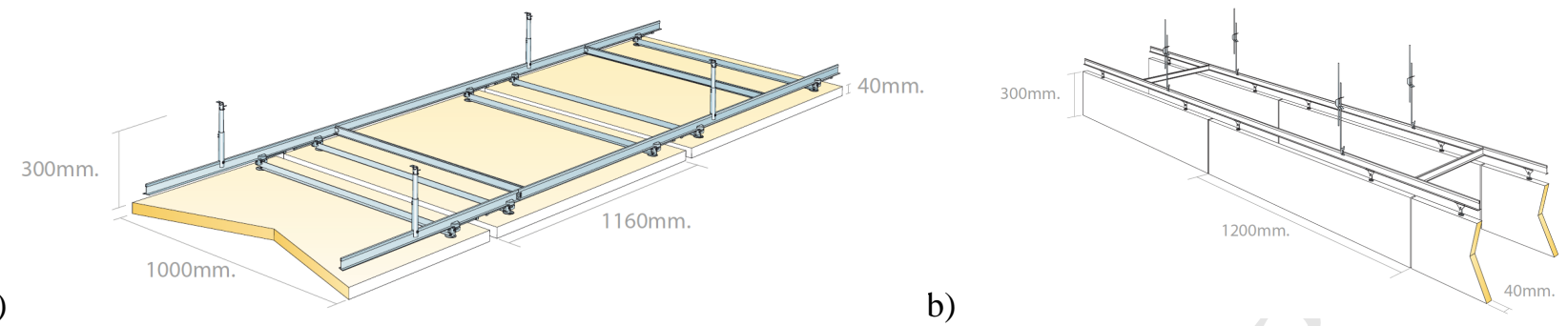

Fig. 2. Dimensions of free-hanging units a) Horizontal panels, b) Vertical panels (baffles). Adapted from [32].

A sensitivity analysis on different parameters was completed and the most common ceiling coverage ratios were identified in a previous study [25]. Among the identified ceiling coverage ratios, three scenarios were chosen and studied with free-hanging horizontal sound absorbers. The panels were installed at a distance of $300 \mathrm{~mm}$ from the ceiling surface with different ceiling coverage ratios [25]. The comparison of the horizontal panels and vertical baffles were made so that the different solutions provide comparable (as close as possible) sound absorption levels. Sound absorption levels were calculated for each scenario according to [32], and it is provided in Equivalent Absorption Area (EAA) in the octave bands 500 to $1000 \mathrm{~Hz}$. EAA is the Equivalent Absorption Area $\left(\mathrm{m}^{2}\right)$ corresponding to a unit area of totally absorbent material. Calculation details can be found in [33]. Table 1 summarizes the scenarios with horizontal panels.

Table 1. Summary of the scenarios with horizontal panels.

\begin{tabular}{cccc}
\hline Scenario & Coverage ratio & Number of horizontal panels & $\begin{array}{c}\mathbf{A}_{\text {eq }}, \text { Equivalent Absorption } \\
\text { Area (m } \mathbf{m}^{\mathbf{S}} \text { Sabin) }\end{array}$ \\
\hline 1a & $43 \%$ & 8 & 13.3 \\
2a & $60 \%$ & 11 & 18.3 \\
3a & $80 \%$ & 15 & 24.9 \\
\hline
\end{tabular}


A metallic structure was installed to form a grid, so that the sound absorbers can be distributed evenly along the ceiling surface for different ceiling coverage ratios. Fig. 3 shows the installation and layout of the horizontal free-hanging units in the test facility for different ceiling coverage ratios.

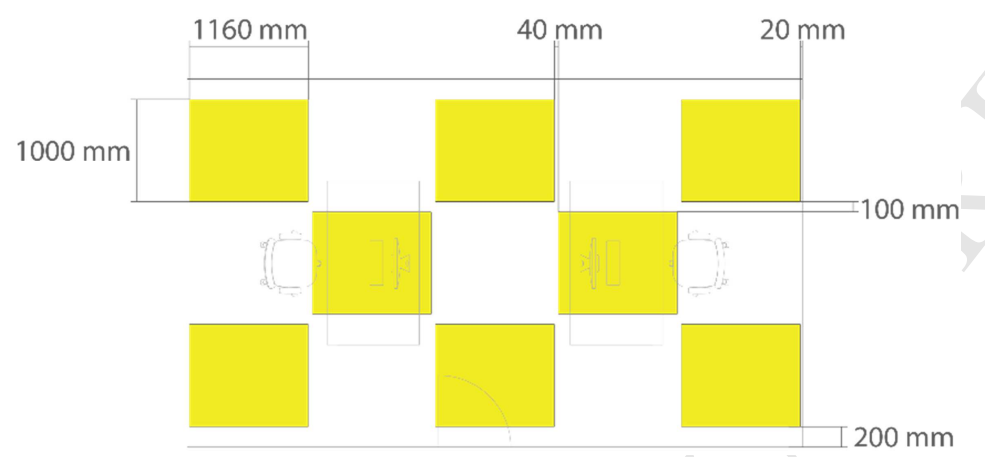

Scenario 1a (43\% coverage ratio)

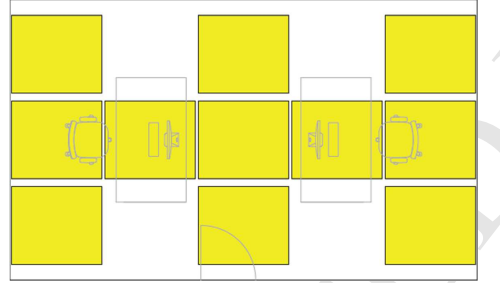

Scenario 2 a $(60 \%$ coverage ratio)

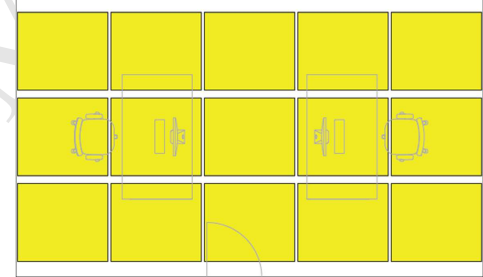

Scenario 3a ( $80 \%$ coverage ratio)

Fig. 3. Grid dimensions and the layout of the horizontal sound absorbers.

Five scenarios were studied with vertical sound absorbers. The vertical panels were also installed at a distance of $300 \mathrm{~mm}$ from the ceiling surface and they were evenly spread along the ceiling area. The selected scenarios were identified as the most reasonable and commonly used acoustic solutions for offices [31]. For comparison purposes, two additional scenarios were studied ( $6 \mathrm{~b}$ and $8 \mathrm{~b}$ in Table 2$)$ matching the sound absorption achieved with horizontal panels [32]. Table 2 summarizes the scenarios with vertical baffles. 
Table 2. Summary of the scenarios with vertical baffles.

\begin{tabular}{|c|c|c|c|c|}
\hline Scenario & $\begin{array}{c}\text { Distance between } \\
\text { baffles [mm] }\end{array}$ & $\begin{array}{c}\text { Sound } \\
\text { absorption } \\
\text { comparable to }\end{array}$ & $\begin{array}{c}\text { Number of } \\
\text { vertical baffles }\end{array}$ & $\begin{array}{c}\mathbf{A}_{\text {eq }}, \text { Equivalent } \\
\text { Absorption Area (m² } \\
\text { Sabin) }\end{array}$ \\
\hline $4 \mathrm{~b}$ & 400 & & 42 & 10.5 \\
\hline $5 b$ & 300 & $1 \mathrm{a}$ & 57 & 14.3 \\
\hline $6 \mathrm{~b}$ & - & $2 \mathrm{a}$ & 78 & 19.5 \\
\hline $7 b$ & 200 & & 87 & 21.8 \\
\hline $8 b$ & - & $3 a$ & 105 & 26.3 \\
\hline
\end{tabular}

Fig. 4 shows the installation and layout of the vertical baffles in the test facility for different ceiling coverage ratios.

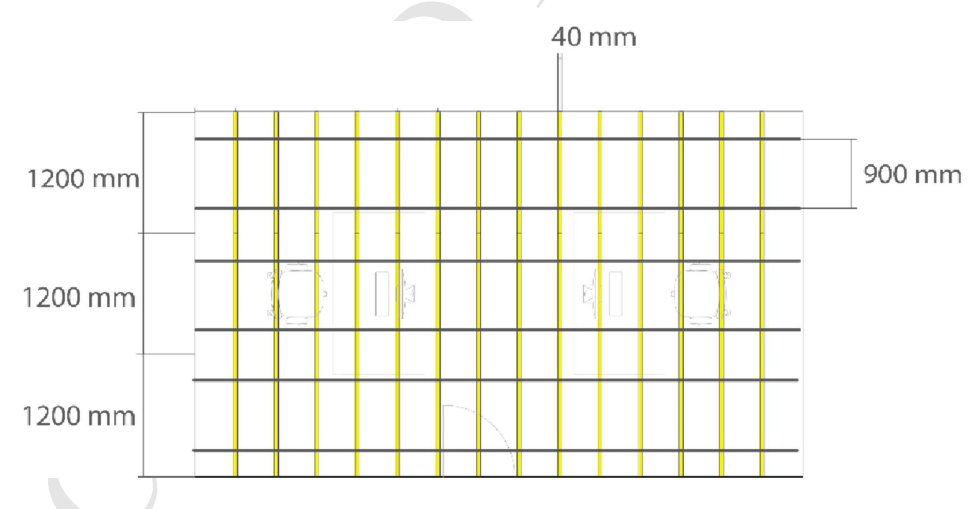

Scenario $4 \mathrm{~b}(400 \mathrm{~mm}$ between baffles) 


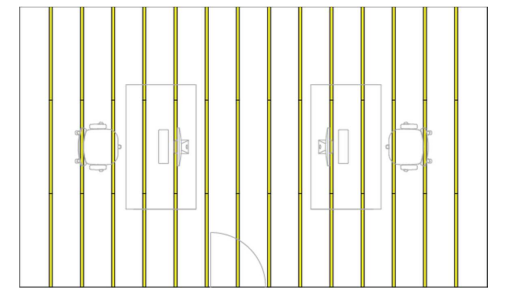

Scenario $5 \mathrm{~b}$ (300 $\mathrm{mm}$ between baffles)

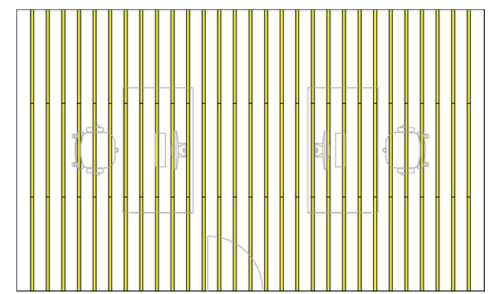

Scenario $7 \mathrm{~b}$ (200 $\mathrm{mm}$ between baffles)

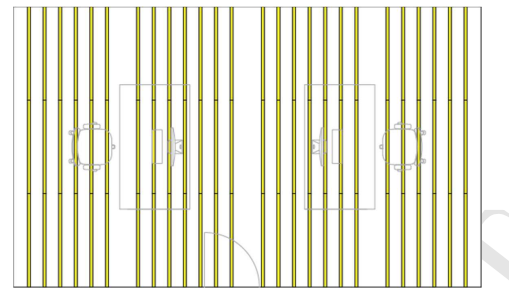

Scenario $6 \mathrm{~b}$ (comparable sound absorption to scenario 2a)

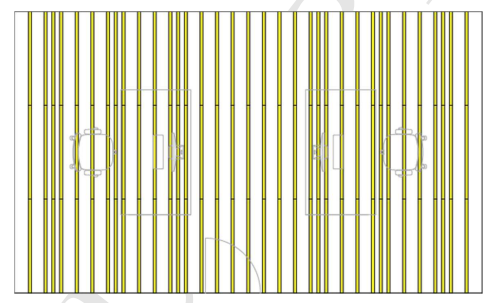

Scenario $8 \mathrm{~b}$ (comparable sound absorption to scenario 3a)

Fig. 4. Grid dimensions and the layout of the vertical baffles.

\subsection{Details of the experimental conditions and measurements}

The experimental conditions were chosen to have a similar operation to an actual two-person office room (ventilation rate, occupancy, internal heat gains, etc.). The room had a balanced ventilation system that was capable of providing airflow at a defined flow rate and temperature. In order to simulate the occupied period of a two-person office room, heat loads were simulated by two thermal dummies, two computers with monitors, four light bulbs and a heating mat placed on a vertical wall representing the solar heat gains from a window on a summer day in Denmark [34]. Table 3 summarizes the experimental conditions. 
Table 3. Summary of the operating conditions during the experiments.

\begin{tabular}{lc}
\hline Constant condition & Value \\
\hline Total heat load $\left[\mathrm{W} / \mathrm{m}^{2}\right]$ & 35 \\
Occupants $[\mathrm{W}]$ & $2 \times 65$ \\
Computer and monitor $[\mathrm{W}]$ & $2 \times 120$ \\
Lighting [W] & $4 \times 50$ \\
Solar gains (heating mat) $[\mathrm{W}]$ & 175 \\
Ventilation supply temperature $\left[{ }^{\circ} \mathrm{C}\right]$ & 20 \\
Ventilation rate $[\mathrm{ACH}]$ & 1.35 \\
Water supply temperature to decks $\left[{ }^{\circ} \mathrm{C}\right]$ & 15 \\
Water flow rate (floor/ceiling) $[\mathrm{kg} / \mathrm{h}]$ & $293 / 283$ \\
\hline
\end{tabular}

One set of experiments (1a, 2a, etc.) took about four days after setting the experimental conditions corresponding to the respective scenario. The behavior of the systems and the thermal indoor environment was monitored constantly. In most cases, reaching the steady-state took three days and the measurements were performed when the steady-state conditions were reached. The thermal indoor environment of the experimental setup was considered to be steady-state when the air and operative temperatures in the measurement location at $0.6 \mathrm{~m}$ height were not varying more than $\pm 0.2^{\circ} \mathrm{C}$ for three hours (determined through preliminary tests and checked for each case during the experiments). Once this condition was fulfilled, the values were recorded for 15 minutes with 10 -second intervals, and the measured values were averaged to obtain the steady-state values.

Measurement instruments were calibrated before the experiments. Air, globe, and surface temperature sensors were calibrated within the temperature range of 17 to $34^{\circ} \mathrm{C}$. The sensors were placed inside a polystyrene calibration box in order to limit the effects of airflow and radiation from the surfaces on the sensors, and this box was placed inside the climate chamber. The temperature inside the calibration box (reference temperature) was monitored by a high-accuracy electronic thermometer, which had an accuracy of $\pm 0.04^{\circ} \mathrm{C}$ in the range of 0 to $150^{\circ} \mathrm{C}$. The temperature inside the chamber was adjusted gradually and the reference temperature was monitored. The readings from the sensors were recorded once the temperature in the calibration box was steady 
and these readings were used to create the calibration curves for the sensors. Other measuring equipment were calibrated by the manufacturers.

The uncertainties of the measured and calculated parameters were determined following the methodology described in [35] and the uncertainties are represented with error bars in the results (confidence interval of 95\%, coverage factor of 2).

The thermal indoor environment in the room was assessed by means of air and globe temperatures. The globe temperatures were measured with a matt gray globe sensor, $40 \mathrm{~mm}$ in diameter. This sensor has the same relative influence of air- and mean radiant temperature as on a person [36] and, thus, at 0.6 and $1.1 \mathrm{~m}$ heights will represent the operative temperature of a sedentary or a standing person, respectively [37]. Sensors to assess the thermal comfort of the occupants were placed at the heights of 0.1, 0.6, 1.1 and $1.7 \mathrm{~m}$ according to EN ISO 7726:2001 [37], Fig. 5.

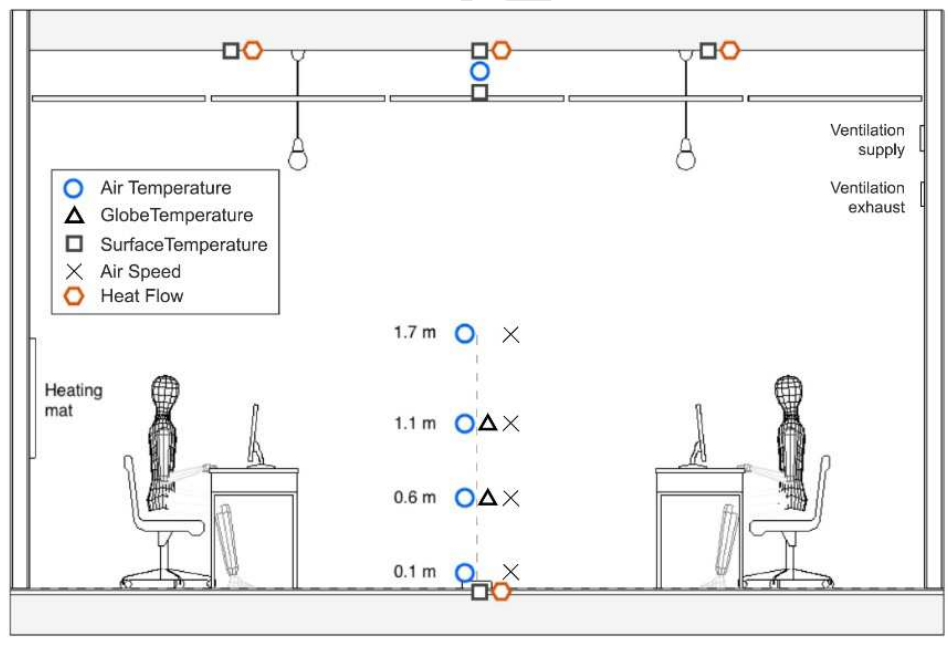

Fig. 5. Position of the measurements and heat loads in the room. 
The air and globe temperatures (globe temperature corresponds to operative temperature at $0.6 \mathrm{~m}$ and at $1.1 \mathrm{~m}$ heights) were measured with thermocouples with an accuracy of $\pm 0.3^{\circ} \mathrm{C}$ [38]. The flow rate, supply and return water temperatures were measured, and the error between the actual and the measured heat flow in the decks was proven to be less than $2 \%$ in a previous study [39].

\subsection{Evaluation of the TABS cooling performance}

This study focuses on evaluating the effects of different scenarios with sound absorbers on the cooling performance of the ceiling decks (ceiling cooling). Under steady-state conditions, the energy balance in the decks is found from Eq. (1).

$q_{\text {pipe }}=q_{\text {up }}+q_{\text {down }}+q_{\text {guard }}$

Where $\mathrm{q}_{\text {pipe }}$ is the heat flow in the pipe [W], $\mathrm{q}_{\text {up }}$ is the heat flow through the ceiling surface [W], $\mathrm{q}_{\mathrm{down}}$ is the heat flow through the floor covering [W] and $\mathrm{q}_{\text {guard }}$ is the heat flow between the sides of the deck and the guard [W]. $\mathrm{q}_{\text {guard }}$ can be neglected since the perimeter of the slab is insulated and the heat loss to the guard only represents 2$3 \%$ of the total heat flows [39]. qup was used to calculate the TABS cooling performance. Fig. 6 shows the heat flows in the decks.

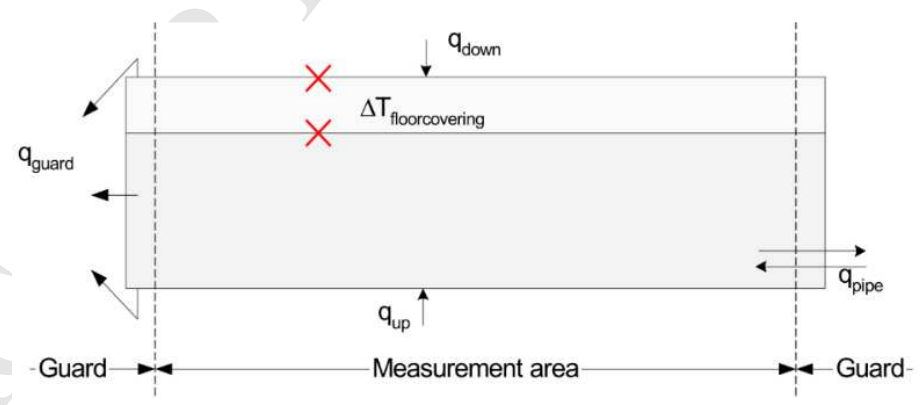

Fig. 6. Illustration of heat flows in the decks [39]. 
The heat flow between the pipes and the concrete decks $\left(\mathrm{q}_{\text {pipe }}\right)$ can be calculated from the measured water flow rate and the temperature difference between the supply and return water flows. $\mathrm{q}_{\text {pipe }}$ can be found from Eq. (2).

$q_{\text {pipe }}=\dot{\mathrm{m}} \cdot c_{p} \cdot\left(T_{\text {supply }}-T_{\text {return }}\right)$

Where, $\dot{\mathrm{m}}$ is the mass flow rate of the fluid in the pipes $[\mathrm{kg} / \mathrm{s}], \mathrm{c}_{\mathrm{p}}$ is the specific heat capacity of the fluid in the pipes $[\mathrm{J} /(\mathrm{kg} \mathrm{K})], \mathrm{T}_{\text {supply }}$ is the supply temperature $\left[{ }^{\circ} \mathrm{C}\right]$ and $\mathrm{T}_{\text {return }}$ is the return temperature of the fluid (water) $\left[{ }^{\circ} \mathrm{C}\right]$.

The heat flow across the floor covering $\left(\mathrm{q}_{\text {down }}\right)$ can be calculated from Eq. (3).

$q_{\text {down }}=\frac{1}{R_{\text {floor covering }}} \cdot \Delta T_{\text {floor covering }}$

Where, $R_{\text {floor covering }}$ is the resistance of the floor covering $\left[\left(\mathrm{m}^{2} \mathrm{~K}\right) / \mathrm{W}\right]$ and $\Delta \mathrm{T}_{\text {floor covering }}$ is the temperature difference between the upper and lower surfaces of the floor covering $\left[{ }^{\circ} \mathrm{C}\right]$.

However, when assessing the cooling performance of the TABS using the cooling capacity of the active surface of the deck, it should be noted that this parameter is influenced by the room temperature and this is expected to vary depending on which scenario is tested. Based on these observations, Weitzmann [39] showed that one parameter remained almost constant for each given scenario, i.e. cooling capacity coefficient $U_{c c}\left(W /\left(m^{2} K\right)\right)$. The cooling capacity coefficient of the ceiling $\left(\mathrm{U}_{\mathrm{cc}}\right)$ is defined as follows.

$U_{c c}=\frac{q_{u p}}{A_{\text {deck }} \cdot\left(T_{\text {room }}-T_{\text {fluid }}\right)}$

Where, $\mathrm{A}_{\text {deck }}$ is the area of the deck $\left[\mathrm{m}^{2}\right], \mathrm{T}_{\text {room }}$ is the operative temperature $\left[{ }^{\circ} \mathrm{C}\right]$ and $\mathrm{T}_{\text {fluid }}$ is the average temperature of the fluid (water) in the decks $\left[{ }^{\circ} \mathrm{C}\right]$. 
The cooling capacity coefficient of the ceiling $\left(\mathrm{U}_{\mathrm{cc}}\right)$ was used to study the effects of sound absorbing units on the cooling performance of TABS.

\subsection{Details of the numerical model}

\subsubsection{Description of the model}

In addition to the experiments conducted in the climate chamber, a dynamic building simulation model of the climate chamber was created with a dynamic simulation software, which allows simulation of a wide range of systems from energy systems to multi-zone buildings and more [30].

Although this simulation model has been validated by comparison to a previous experimental study [13], [14], and used in previous studies [24], [25], the model has been updated for this study to better match the actual conditions in the climate chamber.

Physical components (pumps, valves, etc.) are represented by different Types in the software. The same applies for buildings, and Type 56 is used to represent multi-zone buildings. This Type was used to represent the climate chamber in this study.

The experimental setup and the measurement conditions were recreated as close as possible to the actual conditions in the simulation model. The walls, floor and ceiling structures were modeled using the same material properties and the same construction as in the climate chamber. On the backside, walls, floor and ceiling surfaces were assumed to be facing another room with the same thermal indoor conditions as the climate chamber, in order to simulate the room-in-a-room construction (thermal guard) of the climate chamber.

The floor and ceiling TABS constructions were modeled following the procedure described in the software [40] and according to Fig. 1. The pipes were modeled as an active layer. The concrete used for the floor and ceiling 
slabs had a thermal conductivity of $1.6 \mathrm{~W} /(\mathrm{m} \mathrm{K})$, specific heat capacity of $1 \mathrm{~kJ} /(\mathrm{kg} \mathrm{K})$, and a density of 2300 $\mathrm{kg} / \mathrm{m}^{3}$.

The cavities in the hollow core concrete decks were not modeled. A previous study [39] analyzed the effect of cavity size on the cooling capacity of the concrete deck and found it to be negligible. In addition, the effect of the cavities on the results of this study has been considered negligible mainly because the pipes are embedded close to the surface facing the room $(50 \mathrm{~mm}$ from the lower surface, Fig. 1), where the heat transfer between room and the deck mainly takes place. This heat transfer process is not influenced significantly by the structure above the pipes, in particular, under the steady-state conditions of this study. The effects are discussed further in 3.2.

There was no infiltration. The total heat load, ventilation rate and supply temperature, water supply temperature and water flow rates to the floor and ceiling decks were implemented as defined in Table 3. The simulations were run with 6 min time steps until steady-state conditions have been reached, as described in 2.3 .

During the post processing of the results, some of the outputs from the software (air, operative and ceiling surface temperatures) were used directly and some of them were used to calculate other analyzed parameters using the methodology described in 2.4. The main characteristics of the plug-in for the horizontal sound absorbers are described in the following.

The simulations were performed with the same settings and with the same operating conditions as the experiments, therefore the simulation settings regarding the chamber and its systems are not further described. 


\subsubsection{Description of the plug-in for the horizontal sound absorbers}

A specifically developed plug-in (Type EAE - Ecophon Acoustic Elements) for acoustic elements [23] was used in the model to study the effects of a partially covered ceiling (horizontal sound absorbers) on TABS cooling performance and on thermal indoor environment. Having an accurate simulation tool can give the possibility to designers and researchers to study the effects of horizontal sound absorbers in different buildings during the design phase.

The acoustic element plug-in interacts with the multi-zone building model through inputs and outputs [41]. In the beginning of a time step, the building model calculates room parameters such as the air temperature, ceiling surface temperature, floor surface temperature and the mean radiant temperature for the room (without horizontal sound absorbers) using the standard algorithms in the software. These parameters are then provided to the plug-in, and the plug-in calculates the upper and lower surface temperatures of the horizontal sound absorbers and it calculates the radiative and convective heat exchange in the room with horizontal sound absorbers. Based on the new calculations, a set of radiative gains from the horizontal sound absorbers to the ceiling, floor, and wall surfaces are defined, together with the convective gain from the horizontal sound absorbers to zone air.

In addition to the inputs from the building model, the plug-in requires the following inputs: ceiling coverage ratio, ceiling and room total area, room height and the distance of the horizontal sound absorbers to the ceiling, thickness, thermal conductivity, density and specific heat capacity of the horizontal sound absorbers, and surface emissivity of the upper and lower surfaces of the horizontal sound absorbers and the ceiling and floor surfaces.

Currently, it is only possible to simulate horizontal sound absorbers, and the layout of the sound absorbers are not considered in the plug-in; it is assumed that horizontal panels are clustered in the center of the room [41]. 
Further documentation and details of the implementation of the plug-in are given in [41] (including the calculation of the new mean radiant temperature for the room), and the details of the thermal model of the plugin (i.e. how conduction, convection and radiation are treated) are given in details by Lombard [23].

\section{Results and discussion}

The results of and the discussions regarding the measurements and the simulations are presented in the following.

3.1. Comparison of the effects of horizontal panels and vertical baffles

Fig. 7 shows the comparison of the cooling capacity coefficient and its reduction between scenarios with horizontal panels and vertical baffles.

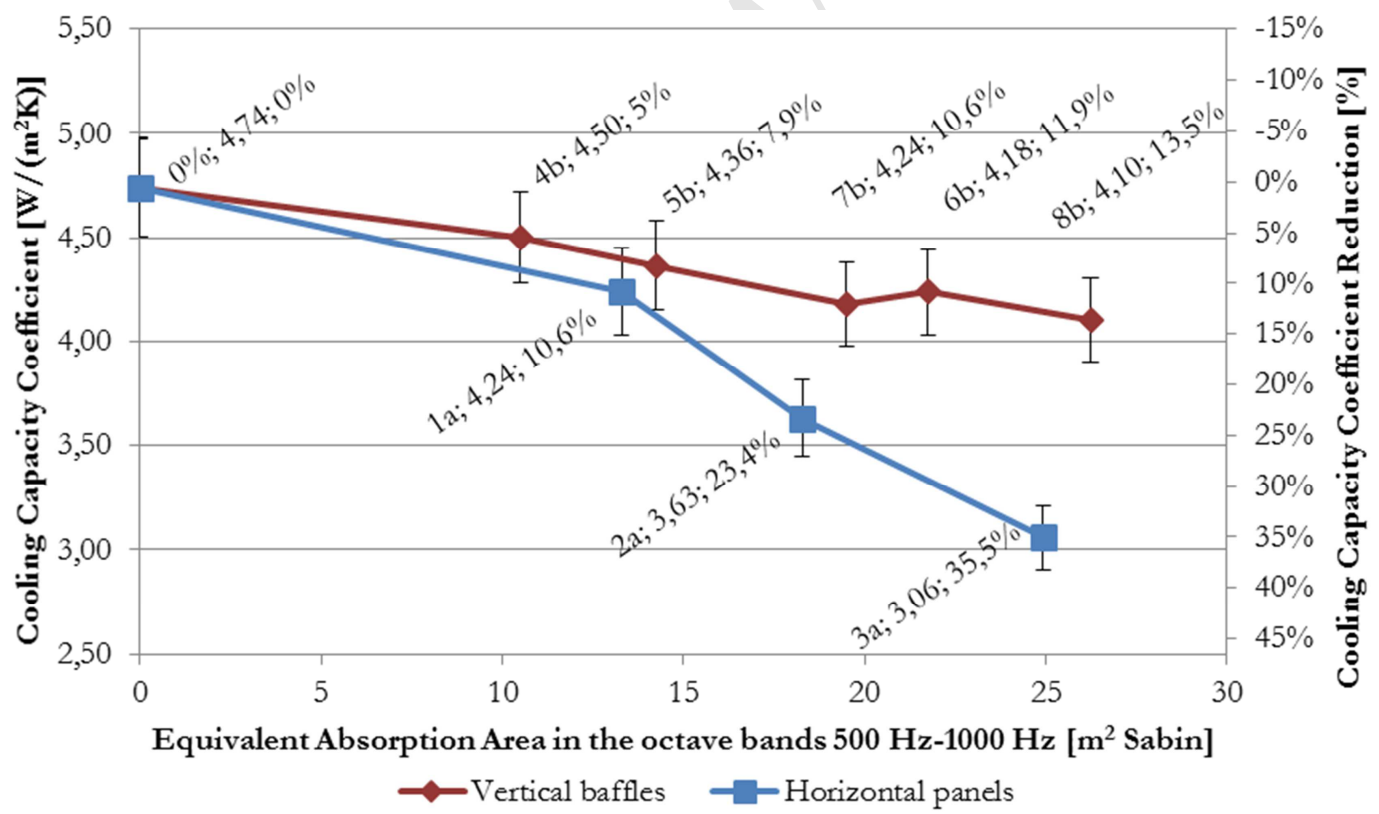

Fig. 7. Cooling capacity coefficients and reduction in the cooling performance for horizontal and vertical panels as a function of the equivalent sound absorption in the mid-frequencies. 
Fig. 7 shows that the cooling performance of TABS decreases when the ceiling surface coverage increases. The heat exchange between the room (surfaces and room air) and the TABS is hindered when the ceiling is covered with free-hanging horizontal sound absorbers; the horizontal panels block partly the radiative and convective heat exchanges between the TABS surface and the heat sources in the room and the room air. For the horizontal panels, compared to the bare-ceiling scenario, the cooling performance of TABS decreased by $10.6 \%$ for a ceiling coverage ratio of $43 \%$ (1a), by $23.4 \%$ for $60 \%$ coverage (2a) and by $35.5 \%$ for $80 \%$ coverage (3a).

The vertical baffles also affect the cooling performance of TABS. The cooling performance decreases as the number of baffles increases. The reduction of the cooling capacity coefficient was $5 \%$ when the distance between the baffles was $400 \mathrm{~mm}$ (4b), $7.9 \%$ when the distance between the baffles was $300 \mathrm{~mm}(5 \mathrm{~b})$, and was $10.6 \%$ when the distance between the baffles was $200 \mathrm{~mm}$ (7b). The results also show that the cooling performance decreased by $11.9 \%$ (6b) and by $13.5 \%$ (8b) in the cases corresponding to the horizontal panels with $60 \%$ and $80 \%$ ceiling coverage ratios, respectively.

The reduction in heat removed by the TABS is less pronounced with vertical sound absorbers for comparable levels of sound absorption. For low sound absorption levels, the cooling performance of TABS remains similar for horizontal and vertical panels. However, for higher sound absorption levels, horizontal panels have a higher influence on the cooling performance of TABS than vertical baffles.

Fig. 8 shows the air temperature stratification in the room and ceiling surface temperatures for scenarios with horizontal panels and vertical baffles. 


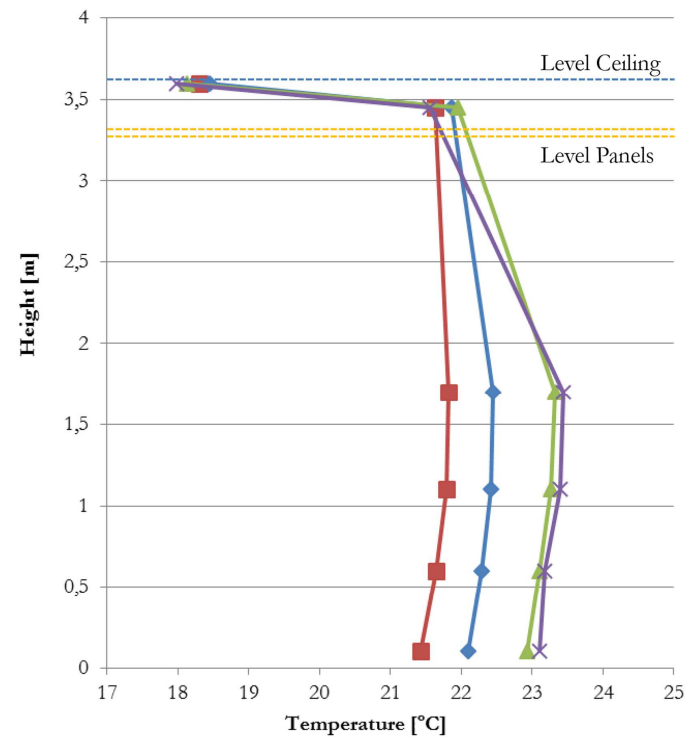

a)

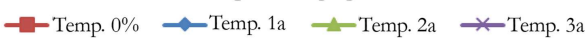

b)

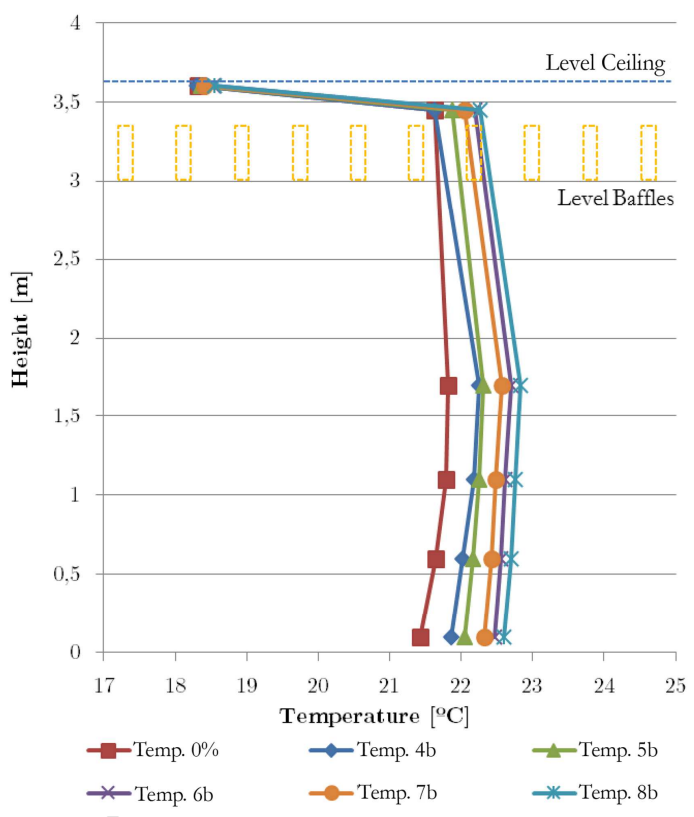

Fig. 8. Measured air temperatures at different heights and ceiling surface temperatures with a) Horizontal panels, b) Vertical baffles.

The results in Fig. 8 show that the air temperature difference between the plenum (space between the acoustic panels and the ceiling) and $0.6 \mathrm{~m}$ above the floor was $0.6 \mathrm{~K}$ for $43 \%$ coverage, $1.4 \mathrm{~K}$ for $60 \%$ coverage and 1.8 $\mathrm{K}$ for $80 \%$ coverage, whereas it was $0.2 \mathrm{~K}$ for the reference case (bare-ceiling). With vertical baffles, the air temperature difference between the plenum and $0.6 \mathrm{~m}$ above the floor was between 0.4 and $0.7 \mathrm{~K}$.

When horizontal sound absorbers were used, there was stagnation of cold air in the plenum (air temperature in the plenum was almost constant) and there was a noticeable temperature difference between the air in the plenum and the room air. When vertical baffles were used, cold air stagnation in the plenum was not observed. There was a good mixing of the room air; temperature in the plenum was increasing, showing that there was mixing and that the thermal plumes from the room were reaching the ceiling. 
The results show that the presence of horizontal sound absorbers blocks partially the radiative heat exchange and prevents convective flows and thermal plumes from reaching the chilled ceiling surface and this effect became more pronounced at higher ceiling coverage ratios.

Fig. 9 shows the increase of operative temperature in the room for different ceiling coverage ratios with horizontal panels, and vertical baffles.

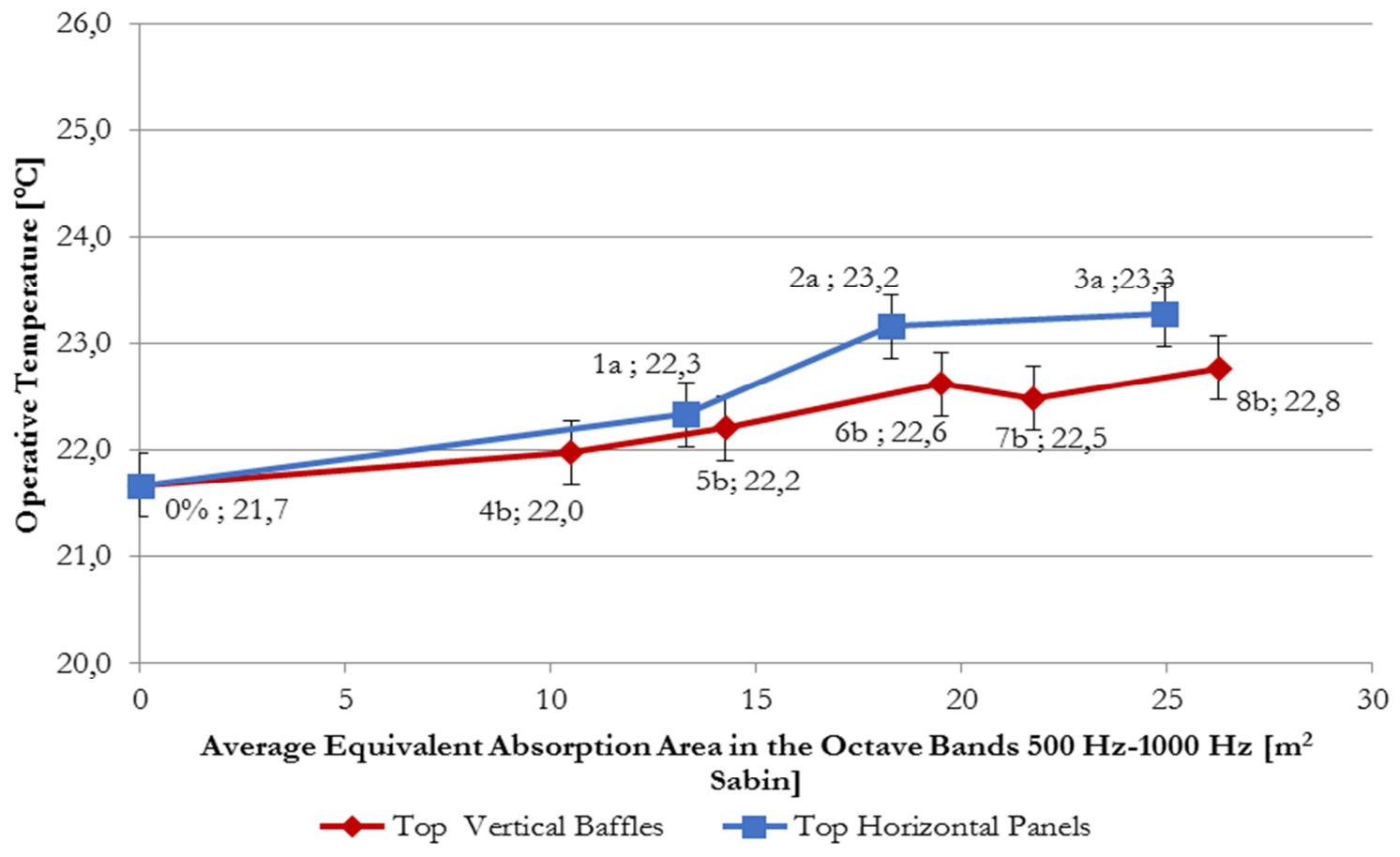

Fig. 9. Increase in operative temperature (at $0.6 \mathrm{~m}$ height) for horizontal panels and vertical baffles.

The operative temperature in the occupied space increases because of the reduction in the cooling performance (heat removed by the TABS surface). In the case of horizontal panels, this increase was $0.6,1.5$ and $1.6 \mathrm{~K}$ for $43 \%, 60 \%$ and $80 \%$ coverage, respectively. In the case of the vertical baffles, the operative temperature in the room increased by $0.3 \mathrm{~K}$ for $4 \mathrm{~b}, 0.5 \mathrm{~K}$ for $5 \mathrm{~b}$ and by $0.8 \mathrm{~K}$ for $7 \mathrm{~b}$. When using the vertical baffles, the 
temperature increase in the room was $0.9(6 \mathrm{~b})$ and $1.1 \mathrm{~K}(8 \mathrm{~b})$ in the cases corresponding to the horizontal panels with $60 \%$ and $80 \%$ ceiling coverage ratios, respectively.

\subsection{Comparison of the measurement results and simulation results for horizontal panels}

Fig. 10 shows the comparison of cooling capacity coefficient and cooling capacity coefficient reduction between the measurements in the full-scale test facility and the results from the simulations.

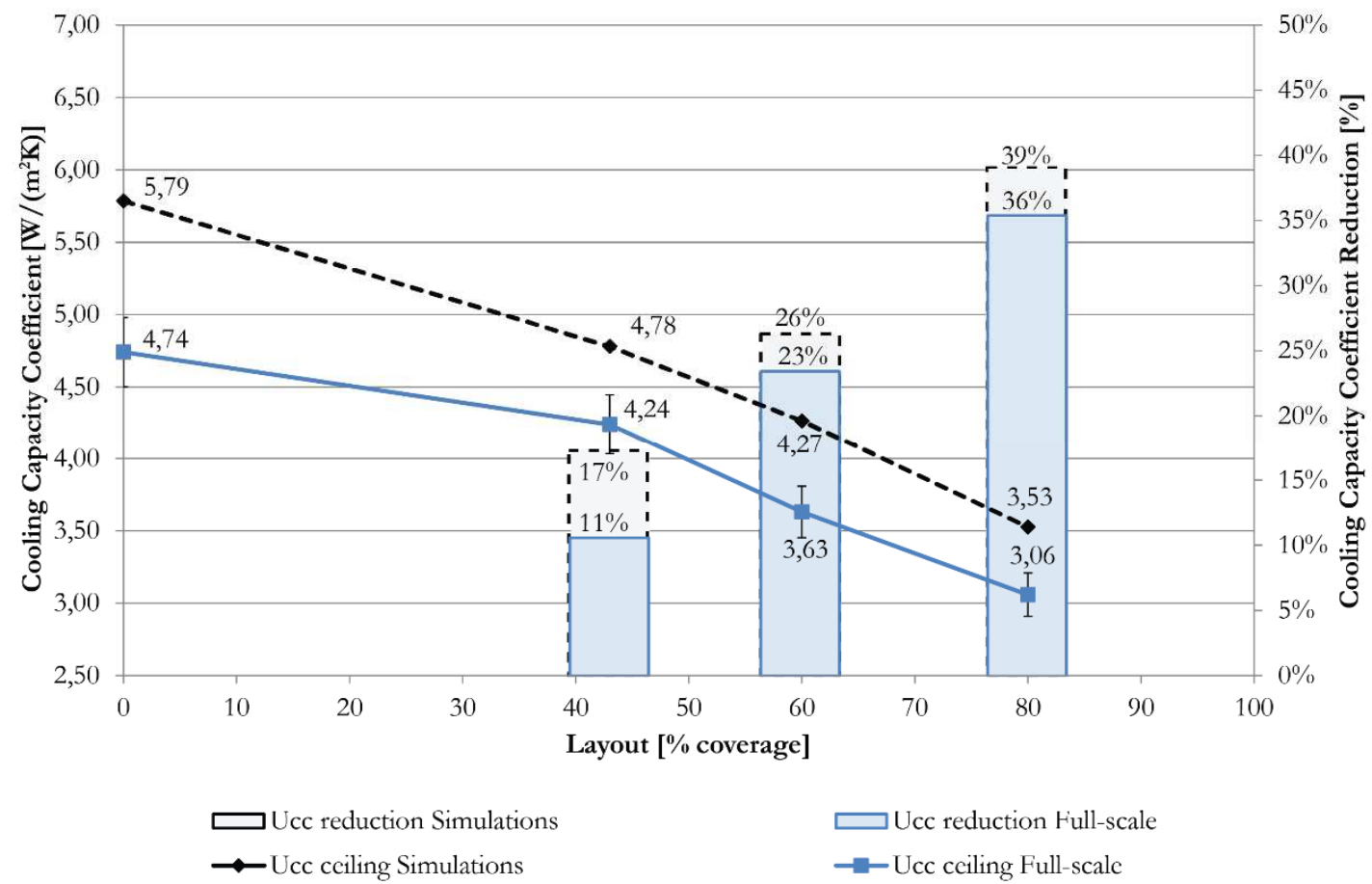

Fig. 10. Comparison of the cooling capacity coefficient and its reduction between full-scale measurements and simulations as a function of the ceiling surface area covered.

The measurements show a cooling capacity reduction of $11 \%, 23 \%$ and $36 \%$ for $43 \%, 60 \%$ and $80 \%$ coverage ratios, respectively. According to the simulations, the cooling capacity decreased by $17 \%, 26 \%$ and $39 \%$ for $43 \%, 60 \%$ and $80 \%$ coverage ratios, respectively. The measurements and the simulations show close values in 
terms of cooling capacity coefficient reduction for higher ceiling coverage ratios; however, for the $43 \%$ ceiling coverage ratio there is a remarkable difference between the reduction predicted by the simulations and by the measurements. This difference could be due to the higher sensitivity of the simulation model to the actual panel layout for lower ceiling coverage ratios. The higher reduction in the cooling capacity predicted by the simulations could be due to the limitation of the simulation model in treating the actual panel layout, and assuming that all the panels are clustered in the center of the ceiling. A previous experimental study showed that with a ceiling coverage ratio of $58 \%$, the cooling capacity reduction was $33 \%$ with evenly distributed panels while it was $37 \%$ when the panels were clustered together, for the same ceiling coverage ratio [16].

Although the experimental results and the simulation results show close reductions in the cooling capacity coefficient, the simulation results overestimate the cooling capacity coefficient of the ceiling compared to the full-scale measurements within a range of $13 \%$ to $22 \%$. This behavior requires further modifications to the simulation model. The difference in the cooling capacity coefficients between the experiments and the simulations are mainly due to the differences in the heat removed by the ceiling surface, and due to the difference in the heat removed by the ventilation (in the simulations, the fraction of the heat that is not removed by the ventilation system is removed by the TABS). Possible other sources of the differences could be limitations in modeling the guard surrounding the climate chamber, which affects the heat transfer from the ceiling slab to the upper side of the slab and temperatures of other surfaces in the room, and the convective heat transfer coefficients used in the simulation model (default values in the software have been used in this study).

Table 4 shows the air and mean radiant temperature comparison between the measurements and simulations, and Fig. 11 shows the comparison of the operative temperatures between the measurements and simulations. 
Table 4. Air and mean radiant temperatures from the simulations and measurements (at $0.6 \mathrm{~m}$ height).

\begin{tabular}{ccccc}
\hline Scenario & $\begin{array}{c}\text { Air temperature, } \\
\text { full-scale }\left[{ }^{\circ} \mathbf{C}\right]\end{array}$ & $\begin{array}{c}\text { Air temperature, } \\
\text { simulations }\left[{ }^{\circ} \mathbf{C}\right]\end{array}$ & $\begin{array}{c}\text { Mean radiant temperature, } \\
\text { full-scale }\left[{ }^{\circ} \mathbf{C}\right]\end{array}$ & $\begin{array}{c}\text { Mean radiant } \\
\text { temperature, } \\
\text { simulations }\left[{ }^{\circ} \mathbf{C}\right]\end{array}$ \\
\hline $0 \%$ & 21.7 & 21.7 & 21.7 & 20.2 \\
$43 \%$ (1a) & 22.3 & 22.4 & 22.4 & 21.1 \\
$60 \%$ (2a) & 23.2 & 22.9 & 23.2 & 21.8 \\
$80 \%$ (3a) & 23.3 & 23.8 & 23.3 & 22.9 \\
\hline
\end{tabular}




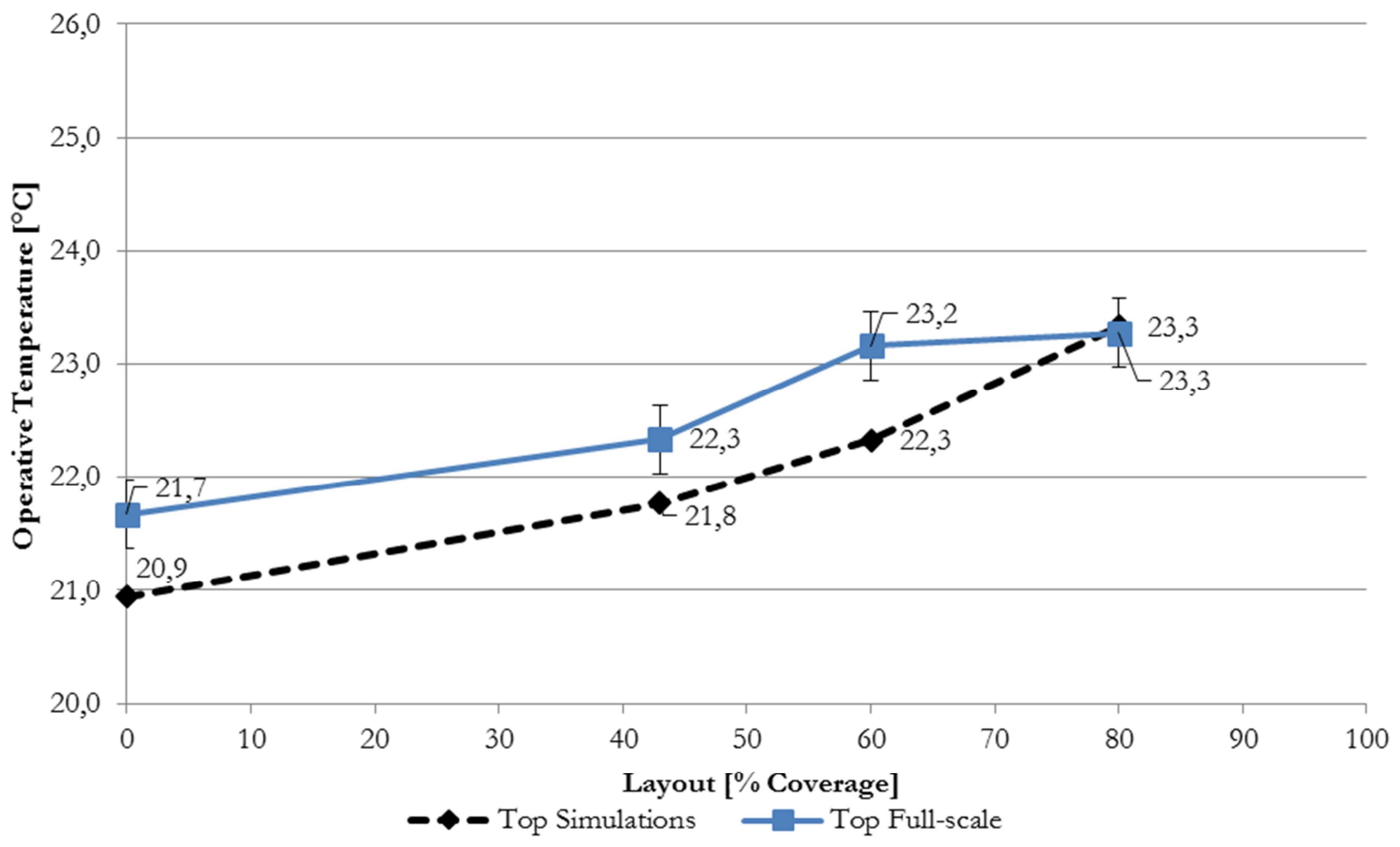

Fig. 11. Operative temperature (at $0.6 \mathrm{~m}$ height) comparison between full-scale measurements and simulations as a function of the ceiling coverage ratio.

The results in Table 4 show that the simulation model is able to predict accurately the air temperature in the room under the investigated conditions. The biggest difference between the simulated and measured air temperatures was observed for a ceiling coverage ratio of $80 \%$. The results also show that the simulation model does not predict the mean radiant temperature as accurately as the air temperature and that the difference between the predicted mean radiant temperature and the measured mean radiant temperature can vary up to 1.5 K. This difference could be partly due to the differences in the convective and radiative portions of the heat loads in the measurements and in the simulations, limitations in modeling the guard (effects on surface temperatures), and due to the limitations in the modeling of the actual layout of the acoustic panels and the measurement 
location in the climate chamber. The simulation model requires improvements regarding the estimation of the mean radiant temperature.

The evaluation of the operative temperature in the room enables combining the effects of air and mean radiant temperature, and although the simulated and measured air temperatures were close, differences in the mean radiant temperatures are reflected to the operative temperatures.

The results in Fig. 11 show that the operative temperature increases due to the reduction in the cooling capacity of TABS. In the climate chamber, this increase was $0.6,1.5$ and $1.6 \mathrm{~K}$ for $43 \%, 60 \%$ and $80 \%$ coverage ratios, respectively. In the case of the simulations, this increase was $0.9,1.4$ and $2.4 \mathrm{~K}$ for $43 \%, 60 \%$ and $80 \%$ coverage ratios, respectively. There is a bigger difference between the simulation results and the measurements of operative temperature compared to the air temperatures in general. For the ceiling coverage ratio of $80 \%$, the simulations and the measurements provide the same operative temperature.

Being able to predict accurately the surface temperature of a radiant cooling system is important for a wider applicability of the model, as the surface temperature can be used to calculate the heat removed by the surface regardless of the radiant system type.

Fig. 12 shows a comparison of the ceiling surface temperature of TABS between the measurements and the results of the simulations. 


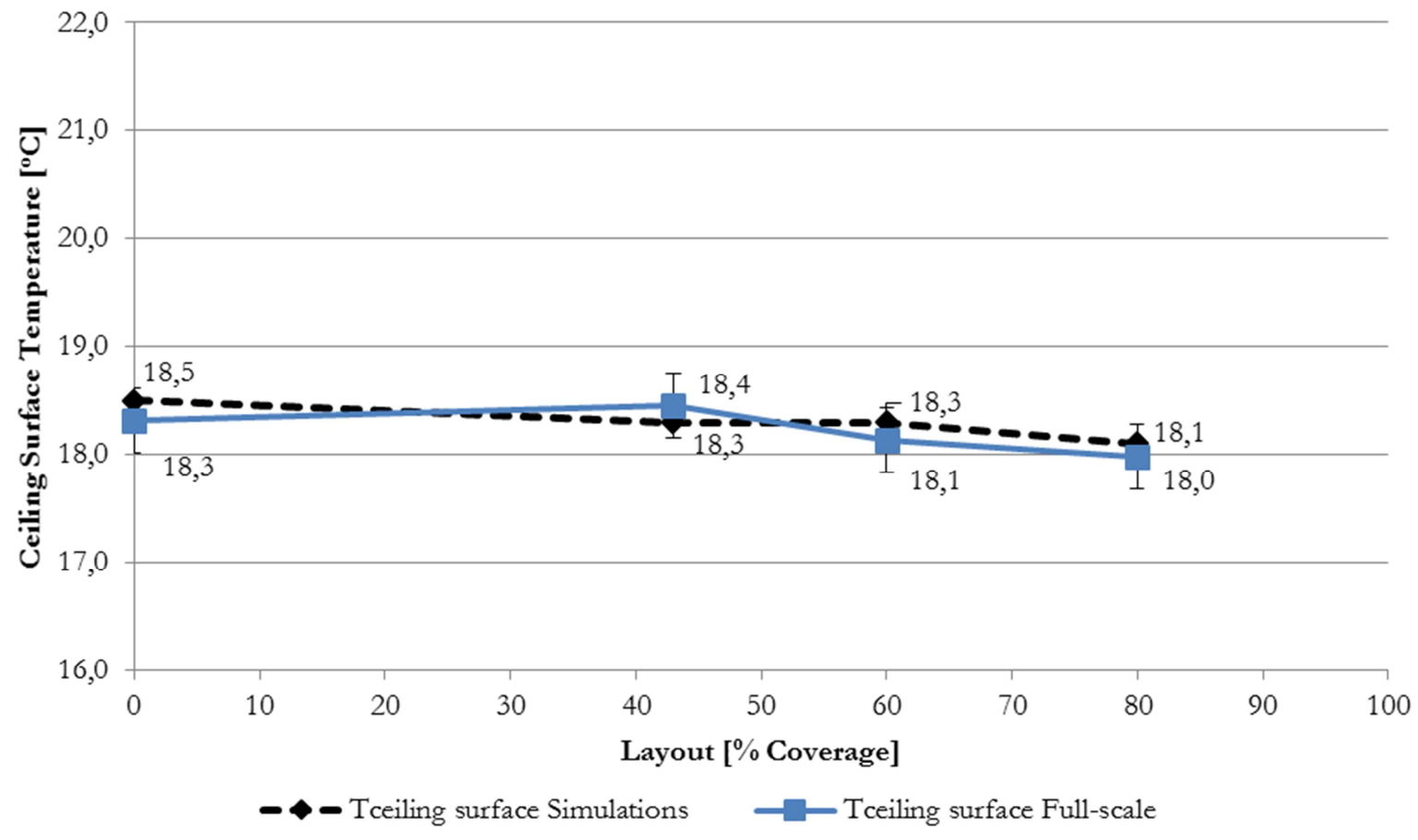

Fig. 12. Ceiling surface temperature comparison between full-scale measurements and simulations as a function of the ceiling surface area covered.

The results of both measurements and the simulations show that the ceiling surface temperature decreases when the ceiling coverage ratio increases, opposite to the behavior of the operative temperature, which increases with higher coverage ratios. This is due to the presence of the horizontal sound absorbers. A cold air layer forms in the plenum, hindering the heat exchange between the occupied zone of the room and TABS, as discussed in 3.1.

Even though the cavities in the hollow core concrete deck were not modeled, the close match of the surface temperatures from the simulations and the measurements show that the slab has been modeled accurately. The results in Fig. 12 show that the simulations with Type EAE can accurately predict the surface temperature of the TABS, and therefore could be used for further analyses in other studies. 


\subsection{Comparison of the results of this study with the literature}

Fig. 13 shows a summary of the results of cooling performance reduction as a function of the ceiling coverage ratio available in literature. It should be noted that the studies presented in Fig. 13 cover a broad range of ceiling coverage ratios and distance between the ceiling and sound absorbers (denoted by $h$ in the legend). The measurement results of this study are presented with yellow circles and the simulation results are presented in green circles.

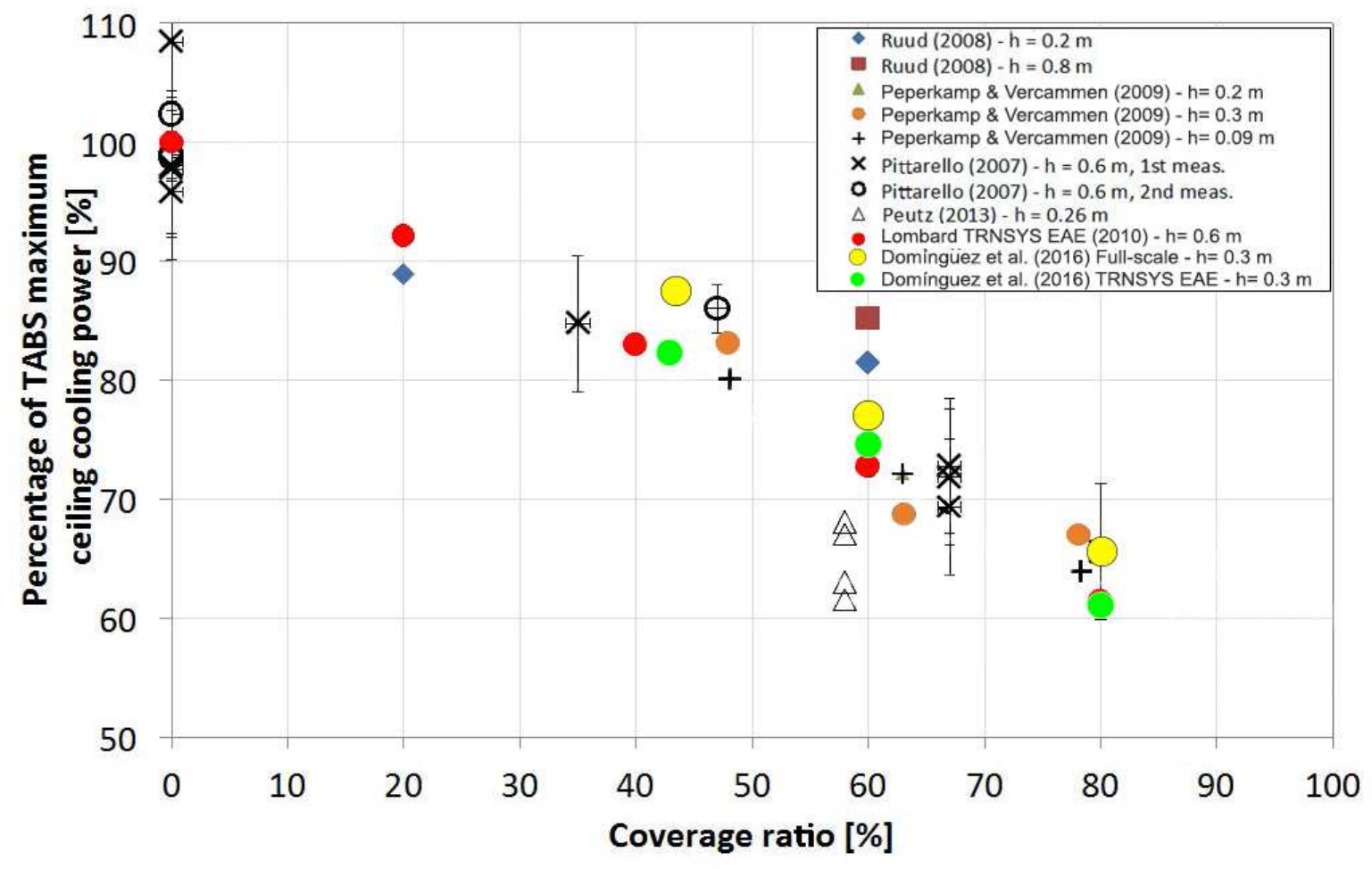

Fig. 13. Summary of the results of cooling performance reduction available in literature as a function of the ceiling coverage ratio (adapted from Lombard [42]). 
The experimental results obtained in this study closely match with the results of the existing studies. The simulation results obtained in this study are very close to the previously obtained simulation results (Lombard 2010 , red circles) and are very close to the experimental results.

\subsection{Strengths and limitations of the simulation model}

The simulation model was able to predict accurately the cooling performance reduction in most cases, while it overestimated the cooling capacity coefficient compared to the measurements. The air temperatures that were predicted by the simulation model and the measured values were very close, while differences existed for mean radiant temperatures, and, hence, for operative temperatures. The ceiling surface temperatures were predicted closely. Both the simulated and measured values of cooling performance reduction of TABS were close to the values found in literature (Fig. 13).

This study intended to provide guideline values on how much the cooling capacity of TABS will decrease with a given ceiling coverage for horizontal panels and vertical baffles. The results show that the TABS and acoustic sound absorbers can be combined and it is possible to quantify the effects of acoustic sound absorbers on the cooling capacity of TABS during the design phase.

The results show that while some aspects of the simulation model could be improved, in its current form it could be used in other studies. Even though not every designer might use this specific simulation software and model, the values given in this study can be used as a first estimate of the effects of acoustic sound absorbers on the cooling capacity of TABS and on thermal indoor environment, together with the experimental results presented in this study. 


\subsection{Overall discussion}

This study analyzed the thermal conditions in a climate chamber by means of air and operative temperatures. Occupant thermal comfort is a function of other factors related to the thermal conditions in the room (draught, floor surface temperatures, radiant asymmetry, and so forth). The air distribution and the airflows in the room will be important factors affecting the occupant thermal comfort. Detailed room air movements under the investigated conditions were analyzed by Computational Fluid Dynamics and reported in another study [43].

The analyses presented in this study did not consider the dynamic effects; the analyses were carried out under steady-state conditions. Both in terms of thermal indoor environment, and in terms of energy use and dimensioning of the systems, further studies should be carried out to identify the effects of horizontal and vertical sound absorbers under dynamic conditions (under a more realistic building operation).

Although it is crucial to quantify the effects of free-hanging sound absorbers on the cooling capacity of TABS and the resulting changes in indoor environment by means of experiments in climate chambers, the effects can be different in real buildings. In real buildings, the effects of sound absorbers on the thermal indoor environment might become less pronounced as occupant behavior will play an important role (e.g. window opening, adjusting the shadings, etc.). Field measurements in real buildings confirm this [19], [21], and a comparison of climate chamber measurements and field measurements is provided in [44].

In addition to the mixing ventilation strategy used in this study, further studies could address the effects of different ventilation strategies (e.g. displacement ventilation) and different supply and exhaust diffuser locations on the cooling performance of TABS and on the thermal indoor environment. Local thermal discomfort should also be investigated as a part of these studies. 
A further issue to investigate is the sensitivity of the cooling system (TABS) to the type (convective and radiative parts of the heat load) and location of the heat loads in the room together with the layout of the sound absorbers. These factors (the relative position of the internal heat sources and the horizontal panels) affect the radiative and convective heat exchange between the TABS surface and the room surfaces, and the room air. Panels positioned directly above the internal heat sources (occupants and equipment) prevent the thermal plumes from reaching the ceiling. A possible solution could be to avoid the presence of horizontal panels directly above the internal heat sources or to increase the space between panels in areas that are presumed to be occupied, i.e. working stations. This preventing effect (masking effect) was not observed in the scenarios with vertical baffles, indicating that the effects of heat load location and panel layout are less pronounced for vertical baffles, as discussed in 3.1.

\section{Conclusions}

The effects of horizontal and vertical free-hanging sound absorbers on the cooling capacity of TABS and on the thermal indoor environment were investigated experimentally in a climate chamber. The effects of horizontal sound absorbers on the performance of TABS and on the thermal indoor environment were also studied by means of dynamic building simulations.

When horizontal sound absorbers were used, the cooling capacity of TABS decreased by $11 \%, 23 \%$ and $36 \%$ for ceiling coverage ratios of $43 \%, 60 \%$ and $80 \%$, respectively. Corresponding operative temperature increase was $0.6,1.5$ and $1.6 \mathrm{~K}$ for $43 \%, 60 \%$ and $80 \%$ coverage, respectively.

When vertical sound absorbers (baffles) were used, the cooling capacity of TABS decreased by $5 \%$ and $11 \%$ when the distance between the baffles was $400 \mathrm{~mm}$ and $200 \mathrm{~mm}$, respectively, and the corresponding operative temperature increase was 0.3 and $0.8 \mathrm{~K}$. When vertical baffles were used to provide the same sound absorption 
levels as the horizontal panels with $43 \%, 60 \%$ and $80 \%$ coverage ratios, cooling capacity of TABS decreased by $8 \%, 12 \%$ and $14 \%$, with a corresponding temperature increase of $0.5,0.9$ and $1.1 \mathrm{~K}$. The use of vertical sound absorbers has a less pronounced effect on the cooling performance of TABS and, therefore, a lower effect on the thermal indoor environment.

Cold air stagnation in the plenum and the consequent decrease in convective heat exchange between the occupied zone of the room and the TABS has been identified as the major cause of the reduction in cooling performance of TABS when horizontal panels were used. Cold air stagnation in the plenum was not observed when vertical baffles were used.

The developed simulation model was able to predict closely the cooling performance reduction of TABS, the ceiling surface temperature, and the thermal indoor environment in most cases. While the model can be improved in certain aspects (prediction of mean radiant temperature and cooling capacity coefficient), the accurate prediction of the surface temperature of the TABS makes the model useful for further studies, which may use differently constructed radiant surface cooling systems.

\section{Acknowledgments}

This study was financially supported by Saint-Gobain Ecophon AB (project no. 8006 Acoustics and Thermal Comfort) and the International Centre for Indoor Environment and Energy, Technical University of Denmark. 


\section{References}

[1] J. Babiak, B. W. Olesen and D. Petráš, Low temperature heating and high temperature cooling, Brussels: REHVA - Federation of European Heating, Ventilation and Air Conditioning Associations, 2009.

[2] R. A. Meierhans, "Room air conditioning by means of overnight cooling of the concrete ceiling," ASHRAE Transactions, V. 102, Pt. 1, pp. 693-697, 1996.

[3] B. W. Olesen, "Low temperature heating and high temperature cooling of buildings using hydronic surface systems," in Proceedings of Healthy Buildings 2000, Vol. 2, Espoo, 2000.

[4] B. W. Olesen, "Using Building Mass To Heat and Cool," ASHRAE Journal, vol. 54, no. 2, pp. 44-52, 2012.

[5] O. B. Kazanci, "Low temperature heating and high temperature cooling in buildings, PhD Thesis," Technical University of Denmark, Kgs. Lyngby, 2016.

[6] H. E. Feustel and C. Stetiu, "Hydronic radiant cooling - preliminary assessment," Energy and Buildings, vol. 22, pp. 193-205, 1995.

[7] B. Olesen, "Radiant Floor Cooling Systems," ASHRAE Journal, vol. 50, no. 9, pp. 16-22, 2008.

[8] O. B. Kazanci, M. Shukuya and B. W. Olesen, "Theoretical analysis of the performance of different cooling strategies with the concept of cool exergy," Building and Environment, no. 100, pp. 102-113, 2016. 
[9] R. A. Meierhans, "Slab cooling and earth coupling," ASHRAE Transactions, V. 99, Pt. 2, pp. 511-518, 1993.

[10] B. Lehmann, V. Dorer and M. Koschenz, "Application range of thermally activated building systems tabs," Energy and Buildings, vol. 39, pp. 593-598, 2007.

[11] C. Stetiu, "Energy and peak power savings potential of radiant cooling systems in US commercial buildings," Energy and Buildings, vol. 30, pp. 127-138, 1999.

[12] K.-N. Rhee, B. W. Olesen and K. W. Kim, "Ten questions about radiant heating and cooling systems," Building and Environment, vol. 112, p. 367-381, 2017.

[13] E. Pittarello, "Influence of acoustical panels on cooling of thermo-active-building-systems (TABS)," Technical University of Denmark, Kgs. Lyngby, 2007.

[14] P. Weitzmann, E. Pittarello and B. W. Olesen, "The cooling capacity of the Thermo Active Building System combined with acoustic ceiling," in Proceedings of the 8th symposium on Building Physics in the Nordic Countries, Copenhagen, 2008.

[15] H. Peperkamp and M. Vercammen, "Thermally activated concrete slabs and suspended ceilings," in Proceedings of NAG/DAGA 2009 International Conference on Acoustics, Rotterdam, 2009.

[16] M. L. Vercammen, "Concrete core activation and suspended ceilings: Designing for comfort, energy efficiency and good acoustics," in Proceedings of Healthy Buildings Europe 2015, Eindhoven, 2015.

[17] S. Ruud, "Testing of acoustic ceiling boards' influence on cooling capacity," SP Technical Research Institute of Sweden, Borås, 2008. 
[18] Peutz, "Ecophon ceiling panels in relation to Thermally Activated Building Systems (TABS) - Climatic chamber test, Report number DB 2805-2E-RA-001," Peutz BV, Mook, 2013.

[19] Y. L. Muet, H. Peperkamp and R. Machner, "Combining thermally activated cooling technology (TABS) and high acoustic demand: Acoustic and thermal results from field measurements," in Proceedings of InterNoise 2013, the 42nd International Congress and Exposition on Noise Control Engineering, Innsbruck, 2013.

[20] Y. L. Muet and P. Lombard, "Combining thermally activated cooling technology (TABS) and high acoustic demand : Acoustic and thermal results from field measurements part 2," in Proceedings of Euronoise 2015, the 10th European Congress and Exposition on Noise Control Engineering, Maastricht, 2015.

[21] R. Machner, "Thermal comfort in office buildings in line with a new German acoustic guideline," Energy Procedia - 6th International Building Physics Conference, IBPC 2015, vol. 78, pp. 2881-2886, 2015.

[22] H. Drotleff, R. Wack, P. Leistner, A. Holm, M. Ziegler and K. SedlBauer, "Integrated sound absorption in thermally activated concrete ceilings - acoustic and thermal effectiveness of sound-absorber strips spaced at intervals," Bauphysik, vol. 33, pp. 274-286, 2011.

[23] P. Lombard, "Measure and model of free hanging sound absorbers impact on thermal comfort," in Proceedings of Eighth Windsor Conference: Counting the cost of comfort in a changing world, Cumberland Lodge, 2014.

[24] N. Rage, O. B. Kazanci and B. W. Olesen, "Validation of a numerical model of acoustic ceiling combined with TABS," in Proceedings of the 12th REHVA World Congress, CLIMA 2016, Aalborg, 2016. 
[25] N. Rage, O. B. Kazanci and B. W. Olesen, "Numerical simulation of the effects of hanging sound absorbers on TABS cooling performance," in Proceedings of the 12th REHVA World Congress, CLIMA 2016, Aalborg, 2016.

[26] N. Langner and D. Bewersdorff, "Thermal and acoustical simulation of open space working areas in commercial buildings equipped with thermally activated building systems," in Proceedings of BS2015: 14th Conference of International Building Performance Simulation Association, Hyderabad, 2015.

[27] J. Fredriksson and M. Sandberg, "The effect of false ceiling on the cooling capacity of passive chilled beams," Building and Environment, vol. 44, p. 1426-1430, 2009.

[28] R. Høseggen, H. M. Mathisen and S. O. Hanssen, "The effect of suspended ceilings on energy performance and thermal comfort," Energy and Buildings, vol. 41, p. 234-245, 2009.

[29] S. Morey, D. Coley and T. Kershaw, "Accessing the Thermal Mass above Suspended Ceilings via a Perimeter Gap: a CFD Study of Naturally Ventilated Spaces," International Journal of Ventilation, vol. 9, pp. $163-175,2010$.

[30] Solar Energy Laboratory, "TRNSYS 17 Manual - Volume 1: "Getting started”," Solar Energy Laboratory, University of Wisconsin-Madison, Madison, 2014.

[31] Ecophon, "Knowledge Guide. Sound absorption - free-hanging units vs. full ceiling," Ecophon, Hyllinge, 2015.

[32] Ecophon, "Ecophon Master MatrixTM Technical Datasheet," Ecophon, Hyllinge, 2015. 
[33] L. M. Domínguez, "Influence of Acoustic Ceiling Units on the Cooling Performance of Thermo-Active Building Systems (TABS)," Technical University of Denmark, Kgs. Lyngby, 2016.

[34] G. K. Pavlov, "Building thermal energy storage, PhD Thesis," Technical University of Denmark, Kgs. Lyngby, 2014.

[35] ISO/IEC Guide 98-3:2008, "Uncertainty of measurement - Part 3: Guide to the expression of uncertainty in measurement (GUM:1995)," International Organization for Standardization, Geneva, 2008.

[36] A. Simone, J. Babiak, M. Bullo, G. Langkilde and B. W. Olesen, "Operative temperature control of radiant surface heating and cooling systems," in Proceedings of Clima 2007 Wellbeing Indoors, Helsinki, 2007.

[37] EN ISO 7726, "Ergonomics of the thermal environment - Instruments for measuring physical quantities," European Committee for Standardization, Brussels, 2001.

[38] A. Simone, B. W. Olesen, J. L. Stoops and A. W. Watkins, "Thermal comfort in commercial kitchens (RP1469): Procedure and physical measurements (Part 1)," HVAC\&R Research, pp. 1001-1015, 2013.

[39] P. Weitzmann, "Modelling building integrated heating and cooling systems, PhD Thesis," Technical University of Denmark, Kgs. Lyngby, 2004.

[40] Solar Energy Laboratory, "TRNSYS 17 Manual - Volume 5: "Multizone Building Modeling with Type56 and TRNBuild"," Solar Energy Laboratory, University of Wisconsin-Madison, Madison, 2012.

[41] Ecophon, "Type Ecophon Acoustic Elements for TRNSYS - User Guide," Ecophon, Hyllinge, 2015. 
[42] P. Lombard, "Thermal model of Ecophon free-hanging sound absorbers for TRNSYS," Saint-Gobain Recherche, 2010.

[43] L. M. Dominguez and J. Fan, "Modelling of a Thermally Activated Building System (TABS) combined with free-hanging acoustic ceiling units using Computational fluid dynamics (CFD)," Submitted to Building Simulation, 2016.

[44] L. M. Dominguez, N. Rage, O. B. Kazanci and B. W. Olesen, "Effects of Free-hanging Horizontal Sound Absorbers on the Cooling Performance of Thermally Activated Building Systems (TABS)," in In Press, Proceedings of ICPEBE 2017: 19th International Conference on People, Ecosystems and Built Environment, Barcelona, 2017. 


\section{Highlights}

- Effects of free-hanging sound absorbers on TABS cooling performance were studied

- Different ceiling coverage ratios with horizontal and vertical panels were studied

- Experimental and dynamic building simulation results are presented

- TABS cooling reduced by $11 \%, 23 \%$ and $36 \%$ for $43 \%, 60 \%$ and $80 \%$ ceiling coverage

- TABS cooling reduced by $8 \%, 12 \%$, and $14 \%$ for similar cases with vertical panels 